\title{
Comparative study of friction stir welding and tungsten inert gas welding process
}

\author{
Ratnesh K. Shukla ${ }^{1}$ and Pravin K. Shah ${ }^{2}$ \\ ${ }^{1}$ Mechanical Engineering Department, Government Engineering College, Majura Gate, Surat- 395001, India \\ ${ }^{2}$ SilverOak College of Engineering \& Technology, Ahmedabad-382481, India \\ ratneshshukla1@yahoo.com; pravinkshah@gmail.com
}

\begin{abstract}
An experimental investigation has been carried out on microstructure, micro hardness distribution, tensile properties and fracture surface morphology of weld butt joints of $6061 \mathrm{~T} 6$ aluminum alloy. Two different welding processes have been considered: a conventional tungsten inert gas (TIG) process and an innovative solid state welding process known as friction stir welding (FSW) process. Micro hardness distribution results showed a general decay of mechanical properties of TIG joints, mainly due to high temperature experienced by the material. Instead, in FSW joint, lower temperatures are involved in the process due to severe plastic deformation induced by the tool motion and lower decay of mechanical properties. In the nugget zone a slight recovery of hardness is observed due to recrystallisation of very fine grain structure. Hence from industrial perspectives, FSW process is very competitive as it saves energy, has higher tensile strength and prevents the joints from fusion related defects.
\end{abstract}

Keywords: Friction stir welding, tungsten inert gas welding, micro hardness, tensile properties, fractography.

Introduction

Friction stir welding (FSW) is a solid state method developed by the welding institute (TWI) (Thomas, 1991) and now being increasingly used in the welding of aluminum. Aluminum alloys find wide applications in aerospace, automobile industries, in ship building, in train wagons and trams, in offshore structures and in bridge constructions due to its light weight and higher strength to weight ratio (Dawes, 1995). FSW is a innovative solid phase welding process in which there is no melting of the material. Hence, FSW is preferred over the commonly used fusion welding techniques for the advantages such as: there are no voids and cracking in the weld, there is no distortion of the work piece, no need of filler materials, no costly weld preparation required, no shielding gas is required during FSW process (Thomas et al., 1997). It is a clean and environment friendly process because there are no harmful effects like arc formation, radiation, release of toxic gas etc. FSW is perhaps the most remarkable and potentially useful welding technique. However, during FSW process using inappropriate welding parameters can cause defects in the joint and deteriorate the mechanical properties of the FSW joints (Cavaliere et al., 2008). Although FSW consistently gives high quality welds, proper use of the process and control of number of parameters is needed to achieve this. To produce the best weld quality, theses parameters have to be determined individually for each new component and alloy (Wei et al., 2007). The quality of friction stir welded joint is controlled by three welding parameters, these are tool's rotation speed, welding speed and welding pressure. Moreira et al. (2007) investigated the fatigue behaviour of joints of FSW and metal inert gas (MIG) welding. Ericsson and Sandstrom (2003) investigated the influence of welding speed on fatigue behaviour of FSW,
MIG and TIG process. Munoz et al. (2008) investigated the microstructure and mechanical properties of FSW and TIG for Al-Mg-Sc alloy. Squillace et al. (2004) investigated the microstructure and pitting corrosion resistance in TIG and FSW joints for 2024-T3 alloy. Taban and Kaluc (2006) studied the microstructure and mechanical properties in MIG, TIG and friction stir welded joints for 5083-H321 aluminum alloy. Though research work of comparative study of FSW with other welding techniques have been reported, it appears that systematic study and detailed comparison between FSW and TIG welding for 6061 T6 aluminum alloy has not been reported yet.

For welding of aluminum alloys with TIG welding alternating current (AC) polarity is used and high heat generation end is continuously changing. Whenever, the electrode becomes positive, more heat is generated (2/3 of total heat) at this end. Similarly, whenever the work piece becomes positive, more heat is generated at this end. In one half cycle, electrode attains maximum heat and in other half cycle the work piece attains minimum heat and this will change in the next cycle (Norman et al., 1999). An electric arc is formed between an inconsumable tungsten electrode and the work piece. The arc provides the thermal energy to melt the work piece as well as the filler material, if necessary. For Al alloys due to their elevated thermal conductivity, the weld penetration remains very shallow (Mondolfo, 2002).

Fig. 1 shows the experimental set up used for present investigation in which a non-consumable rotating tool with specially designed pin and shoulder is inserted at the faying edges of the plates to be welded and traversed along the joint. The two plates are fixed together by means of clamps on the bed and vertical force is applied by fixing the tool on the collet of vertical milling machine. 
The friction between the tool and work piece leads to plastic deformation of work piece. The localized heating softens the material around the pin and combination of tool rotation and translation leads to movement of material from the front of the pin to the back of pin. The weld is generated by deforming the material at temperatures below the melting point. The side where the tool rotation is in the same direction of translation of the welding tool is called advancing side and where the two motions rotation and translation are in opposite direction is called retreating side. The aim of this study is to compare the mechanical properties of TIG and FSW joints of 6061 T6 aluminum alloy.

\section{Materials and methods}

Rolled $4 \mathrm{~mm}$ thick plates of aluminum alloy (AA) 6061 were machined to the required dimensions $(150 \mathrm{~mm} \times 60$ $\mathrm{mm}$ ). The chemical composition of AA 6061 T6 is given in Table 1. Butt joints for TIG welding were prepared using $\mathrm{AlSi}_{5}$ as filler material and argon as shielding gas. The other parameters were: welding current 90 amperes, voltage 18 volts, filler rod diameter $3 \mathrm{~mm}$, welding speed $120 \mathrm{~mm} / \mathrm{min}$, gas flow $20 \mathrm{lit} / \mathrm{min}$.

The plates with same dimensions were friction stir welded by butting two plates together with a rotating tool assembly at $1000 \mathrm{rpm}$ rotational speed and welding speed of $50 \mathrm{~mm} / \mathrm{min}$. CNC milling machine with motor of $11 \mathrm{KW}$ was used for performing the experiment. The material for the tool was tool steel which was hardened to $60 \mathrm{HRC}$. The tool used had shoulder diameter of $14 \mathrm{~mm}$, top pin diameter of $5.5 \mathrm{~mm}$, bottom pin diameter of $3 \mathrm{~mm}$ and pin height $3.85 \mathrm{~mm}$. The pin was left hand threaded and tool was rotated in counterclockwise direction.

Micro structural changes from weld zone to the unaffected base material were examined with optical microscope. For optical microstructure inspection the cross-section of weld zone was polished and then etched by Keller's reagent consisting of $95 \mathrm{ml}$ distill water, $2.5 \mathrm{ml}$ $\mathrm{HNO}_{3}, 1.5 \mathrm{ml} \mathrm{HCl}$ and $1 \mathrm{ml} \mathrm{HF}$. The Vickers hardness profile of the weld zone was measured at mid thickness on a cross section perpendicular to the welding direction using micro hardness tester with $200 \mathrm{gms}$ load for $15 \mathrm{sec}$. The fractured surface of welded specimen was analyzed using scanning electron microscope (SEM). The specimen for tensile test was prepared on a CNC electric discharge wire cut machine according to EN 895: 1995 as shown in Fig. 2. The gauge length for the tensile specimen was $50 \mathrm{~mm}$. The tensile test was performed using computer controlled tensometer at constant cross head speed of $5 \mathrm{~mm} / \mathrm{min}$.

and TIG joint respectively. The base metal contains coarse and elongated grains with uniformly distributed very fine strengthening precipitates. The weld region of FSW joint contains very fine, equiaxed grains and this may be due to dynamic recrystallisation that occurred during FSW process. The fusion zone of TIG welded joints contain dendritic structure and this may be due to fast heating of base metal and fast cooling of molten metal due to welding heat.

The higher strength of the base material is mainly attributed due to presence of alloying elements such as silicon and magnesium. These two elements combine and undergo precipitation reaction and form strengthening precipitates $\beta "-\mathrm{Mg}_{5} \mathrm{Si}_{6}$ as shown by darken particles in fig. 4a. These precipitates are stable at temperatures lower than $200^{\circ} \mathrm{C}$ (Grong, 1997). Fine and uniform distribution of these precipitates throughout the aluminum matrix provides higher strength and hardness to the joints. This precipitate exists in the unaffected base material but is absent in the weld nugget and in the HAZ. In the friction stir welds, the temperatures are over 200$250^{\circ} \mathrm{C}$ during heating and $\beta^{\prime \prime}$ is easily dissolved (Svensson et al., 2000). This $\beta$ " precipitate is mainly responsible for hardening. Svensson et al. (2000) reported that in HAZ precipitates of $\beta^{\prime}-\mathrm{Mg}_{2} \mathrm{Si}$ exists and $\beta^{\prime}$ precipitates have less strengthening effect compared to $\beta$ ", so a lower hardness is obtained. Grong (1997) reported that in HAZ where the temperature are near or less than $300^{\circ} \mathrm{C}$, the precipitation of $\beta^{\prime}$ is very high and as a consequence, the transition from $\beta^{\prime \prime}$ to $\beta^{\prime}$ by dissolution occurs. In the weld nugget, the temperature is higher; therefore $\mathrm{Mg}_{2} \mathrm{Si}$ precipitates go into the solution. On cooling, the time of precipitation is limited, therefore only a small volume fraction of $\beta^{\prime}$ precipitates are formed in the weld nugget (Moreira et al., 2009). The nugget hardness recovery is due to recrystalization of very fine grain structure and by natural aging. In FSW, friction heat softens the welded material at a temperature less than its melting point. The softened material underneath the shoulder is also subjected to extrusion by the rotating tool. It is expected that this process will inherently produce a weld with relatively few residual stress and distortion (Chen \& Kovakevic, 2003).

When aluminum alloys are welded using non-heat treatable $\mathrm{AISi}_{5}$ filler metal to avoid solidification cracking problem, the weld material is composed of fewer strengthening precipitates compared to base metal. In fusion welding even though, large amount of silicon is available in base and filler metal (the available Table 1. Chemical composition of 6061aluminum alloy

\begin{tabular}{|c|c|c|c|c|c|c|c|c|c|}
\hline Element & $\mathrm{Mg}$ & $\mathrm{Si}$ & $\mathrm{Cu}$ & $\mathrm{Mn}$ & $\mathrm{Cr}$ & $\mathrm{Fe}$ & $\begin{array}{l}\text { Ti \& other refining } \\
\text { elements }\end{array}$ & $\mathrm{Al}$ & $\begin{array}{l}\text { present in base metal } \\
\text { alone) for precipitation }\end{array}$ \\
\hline$\%$ & $0.8-1.2$ & $0.4-0.8$ & $0.15-0.4$ & $<0.15$ & $0.2-0.35$ & $<0.3$ & $<0.4$ & Balance & reaction in the weld pool \\
\hline
\end{tabular}

\section{Results and discussion}

Fig. $3 a$ \& $3 b$ shows the macrostructure of TIG and FSW joints respectively. Fig. $4 a, 4 b \& 4 c$ show the optical micrographs of the base material, weld region of $\mathrm{FSW}$ its content is very low. Hence, the weld region of $A A$ 6061, when welded with $\mathrm{AlSi}_{5}$ filler metal usually contains lower amount of strengthening precipitates compared to the base metal region. Therefore the precipitate
"Welding"

http://www.indjst.org
Shukla \& Shah Indian J.Sci.Technol. 


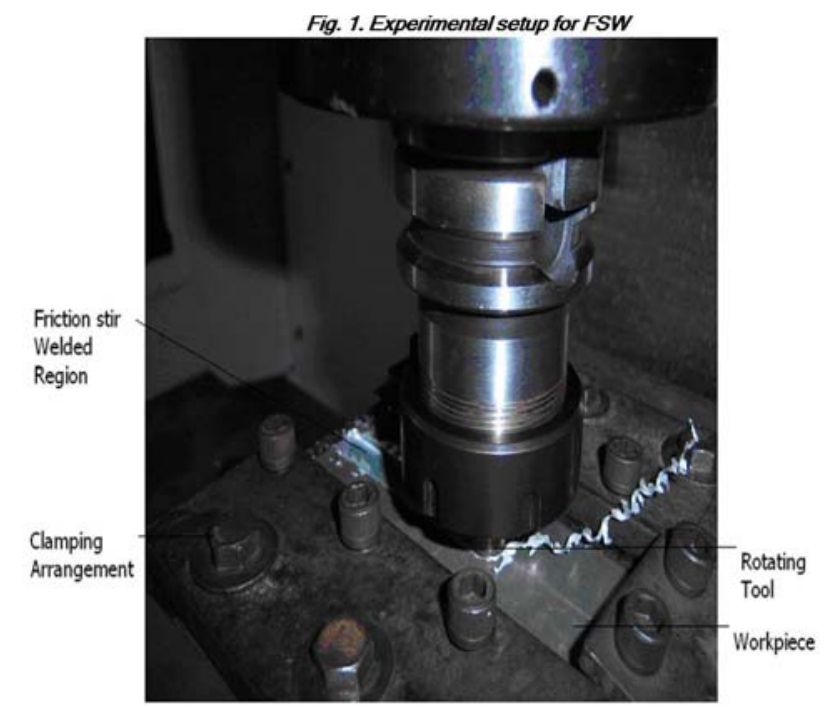

Fig. 3a. Macrostructure of T/G joint

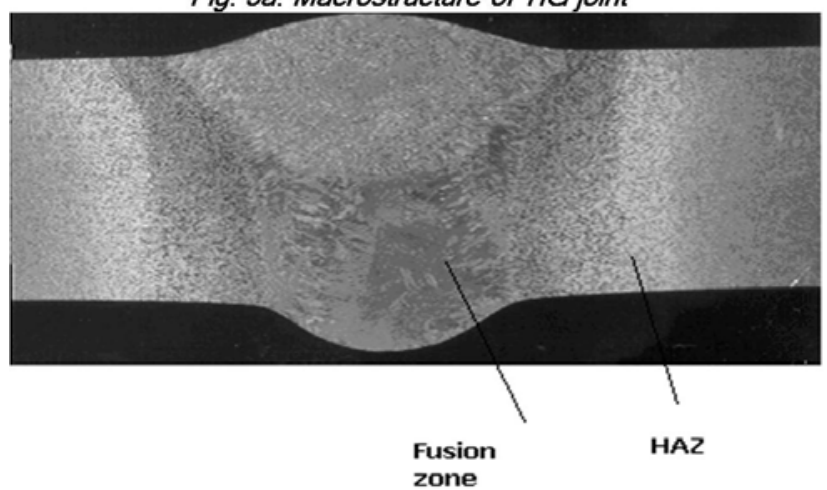

Fig. 3b. Macrostructure of FSW joint

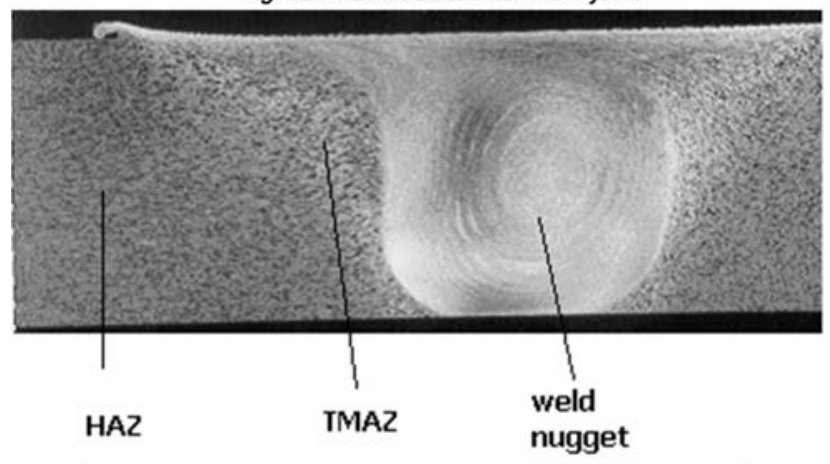

Fig.5. Micro hardness distribution for TIG and FSW joint

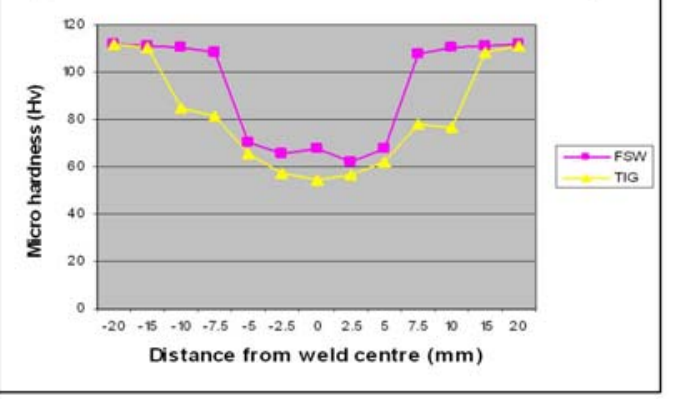

Vol. 3 No. 6 (June 2010)

ISSN: 0974- 6846
Fig. 2. Schematic of tensile test specimen

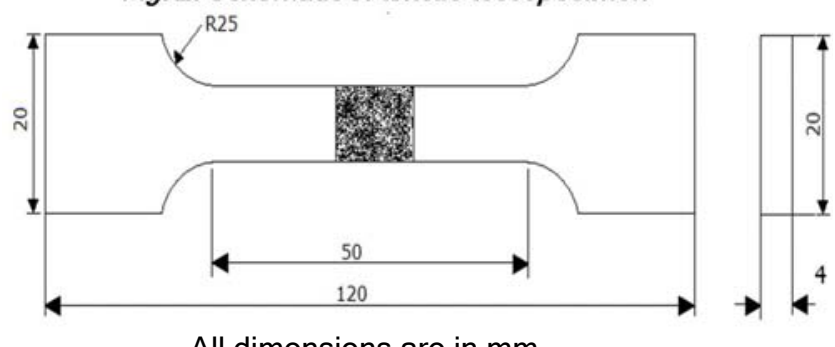

All dimensions are in $\mathrm{mm}$

Fig. 4a. Microstructure of 6061 at $100 X$.

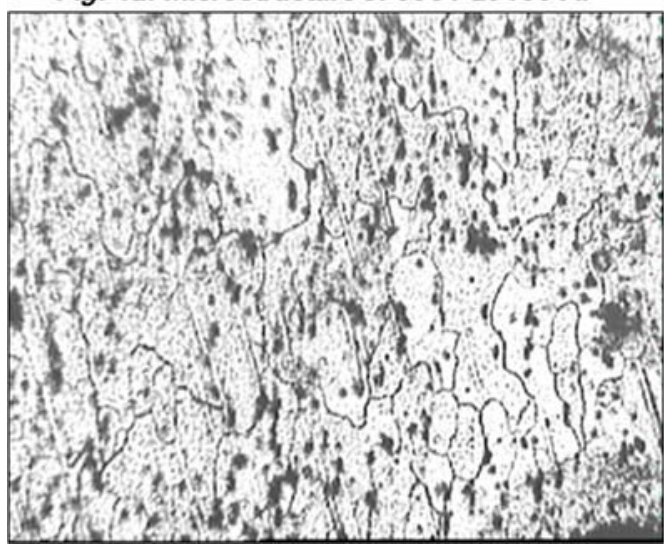

Fig. 4b. Microstructure of weld zone of FSW at $100 X$.

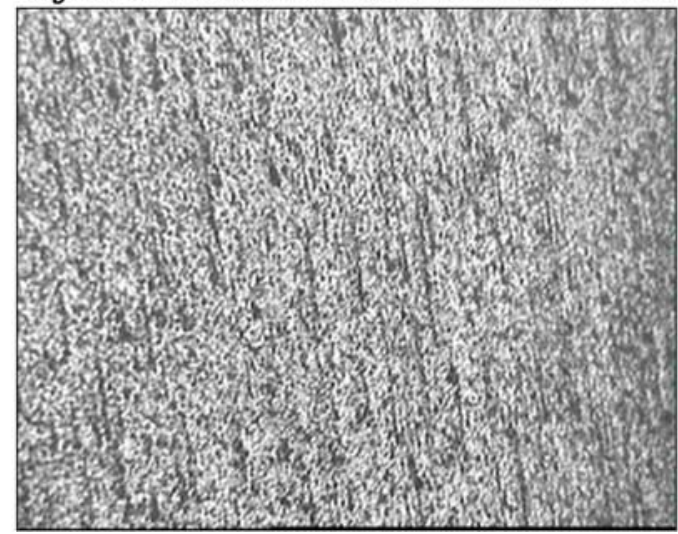

Fig. 4c Microstructure of weld zone of TIG at $100 X$.

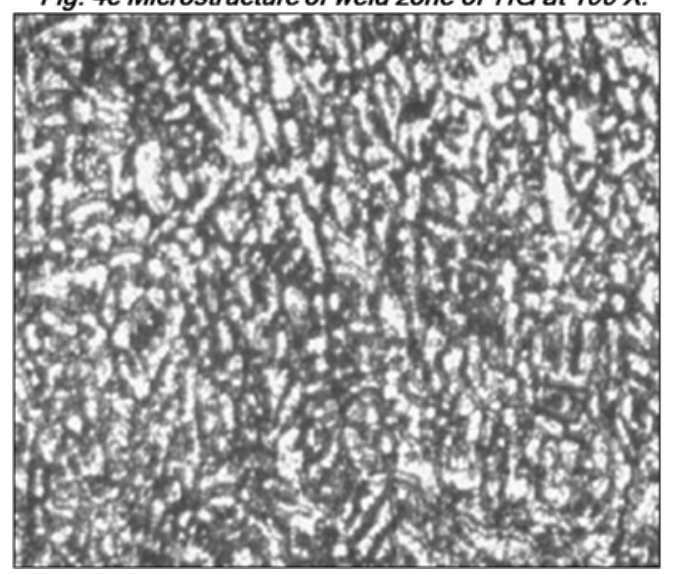

Research article

CIndian Society for Education and Environment (iSee)
"Welding" http://www.indjst.org
Shukla \& Shah Indian J.Sci.Technol. 
strengthening of $\mathrm{Mg}_{2} \mathrm{Si}$ precipitates is weak in TIG joints. On the other hand, the weld region of FSW joint contains the alloying elements similar to the base metal.

Micro hardness

Fig. 5 shows the micro hardness distribution for TIG and FSW joint. The micro hardness of the base metal was $111 \mathrm{Hv}$. The micro hardness of TIG joint in the weld metal region was $55 \mathrm{Hv}$. This shows that the hardness is reduced in TIG joint due to higher heat input and use of lower hardness $\mathrm{AlSi}_{5}$ filler metal. The micro hardness of FSW joint in the weld region is $70 \mathrm{Hv}$. In FSW joint lowest hardness is observed on the advancing side which $62 \mathrm{Hv}$. The hardness is lower than the base metal due to dissolution of strengthening precipitates during the weld thermal cycle. However, FSW showed higher micro hardness compared to TIG joint due to shear stresses induced by tool motion which lead to generation of very fine grain structure, which allows a partial recovery of hardness. In case of TIG welding, very high arc temperature increases the peak temperature of the molten weld pool causing a slow cooling rate. This slow cooling rate, in turn, causes relatively wider dendritic spacing in the fusion zone. These microstructures generally offer lower resistance to indentation and this may be one of the reasons for lower hardness and inferior tensile properties compared to FSW joints.

\section{Tensile properties}

The ultimate tensile strength of base and welded metals are shown in Table 2. Fig. 6 shows images of fractured tensile specimen. The tensile properties and elongation of both TIG and FSW joint is far lower than the parent material. These results are consistent with the observations reported by Ericsson and Sandstrom (2003) and Munoz et al. (2008). These results indicate that softening effect has occurred in aluminum alloy. The tensile properties and fracture
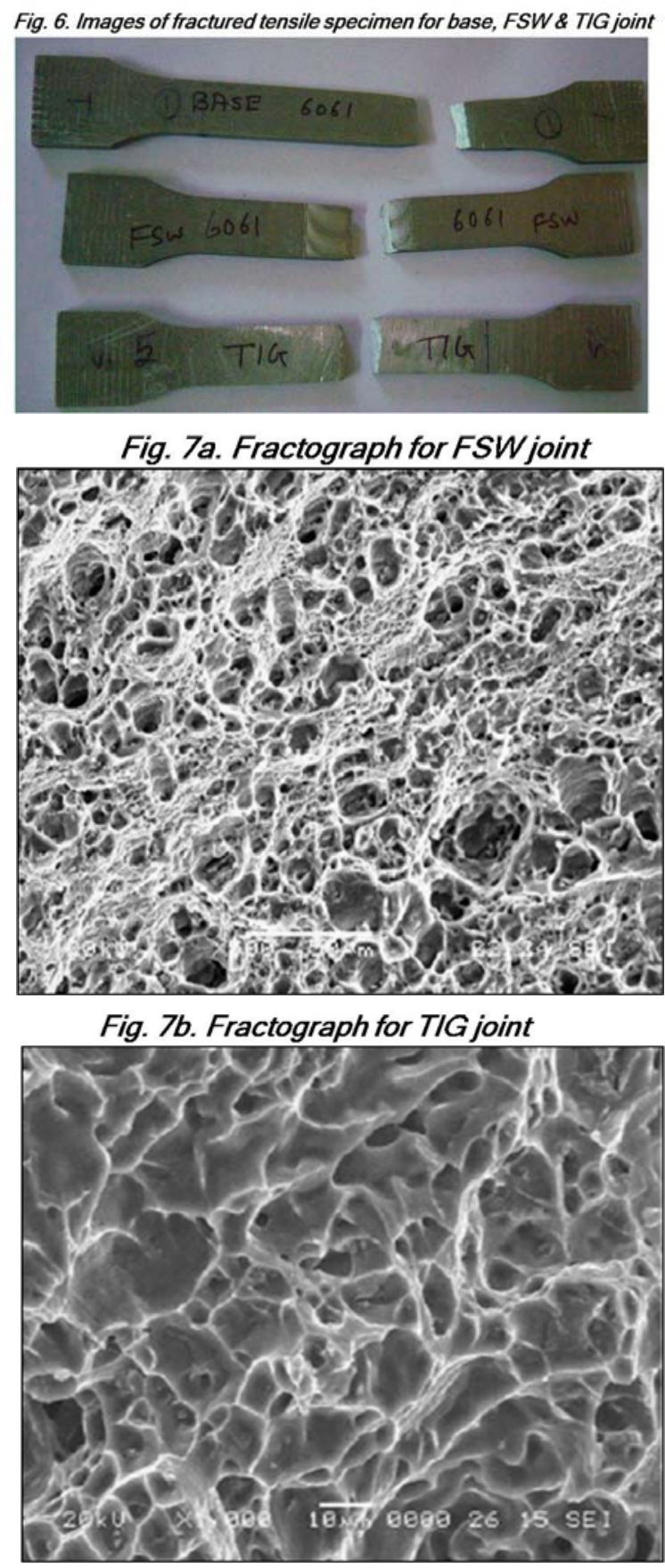

fracture locations of the joints are to a large extent dependent on the hardness distributions of the joints (Liu et al., 2003). Hardness degradation region composed of weld nugget, TMAZ and HAZ has occurred in the joints, thus the tensile properties of the joints are lower than the parent material. It is found that, in FSW the fracture location is between weld nugget and the thermo mechanically affected zone (TMAZ) on the advancing side. In practice the reason for the fracture near the interface between the weld nugget and the TMAZ is the remarkable difference in the internal structure between the weld nugget and TMAZ. The weld nugget is composed of fine equiaxed grains and TMAZ is composed of coarsebent recovered grains (Sato et al., 1999). Therefore the interface between weld nugget and TMAZ becomes a weaker region and the joint is fractured at this interface during the tensile testing. The percentage elongation of FSW joint is higher than TIG joint which shows FSW exhibited higher ductility values compared to TIG joint. Joint efficiency is the ratio between ultimate tensile strength of welded joint to that of base metal. FSW joint exhibited higher efficiency $(51 \%)$ compared to TIG joint $(44.5 \%)$. Fractography

For both FSW and TIG joint the fracture location was in weld region. The fractured surface of tensile specimens of welded joints was analyzed using scanning electron microscope to reveal the surface morphology. Fig. 7 a \& 7b shows fractrography for FSW and TIG joints respectively. The fractrography consists of dimples, which is indication that the tensile specimen failed in a ductile manner under the action of tensile loading. An appreciable difference exists in the size of the dimples

Table 2. Ultimate tensile strength of base \& welded metals

\begin{tabular}{|c|c|c|}
\hline Specimen & Ultimate tensile strength (MPa) & \% Elongation \\
\hline $\begin{array}{c}\text { Base material } \\
\text { 6061 T6 }\end{array}$ & 313.6 & 18 \\
\hline FSW 6061T6 & 159.9 & 5.5 \\
\hline TIG 6061 T6 & 139.6 & 4.5 \\
\hline
\end{tabular}


with respect to welding processes. Coarse dimples are seen in TIG joint and fine dimples in FSW joint. Since fine dimples are characteristic feature of ductile failure, FSW joints have shown higher ductility compared to TIG joint. The dimple size has direct proportional relationship with strength and ductility. i.e. if the dimple size is finer, then the strength and ductility of the respective joint is higher and vice versa (Lin et al., 2003).

\section{Conclusions}

On the basis of experimental investigation carried out on welded joints of AA 6061 T6 prepared according to FSW and TIG processes, the following conclusions are drawn:

1.The formation of fine, equiaxed grains and uniformly distributed very fine strengthening precipitates in the weld region is the reason for superior tensile properties of FSW joints compared to TIG joints.

2. The fractography of FSW joint revealed fine dimples and TIG joint revealed coarse dimples, which shows that FSW joints have higher ductility compared to TIG joints.

3.FSW joint exhibited higher strength values ( $51 \%$ of base material) compared to TIG joint (44.5\%).

4. Micro hardness tests confirm the general decay of mechanical properties induced by higher temperature experienced by material in case of TIG joint.

5. Micro hardness tests performed in case of FSW joint shows great differences among four different zones: nugget zone, TMAZ, HAZ (Heat affected zone) and base metal. The first two zones are characteristized by a general drop of mechanical properties, even though nugget zone showed a slight recovery due to fine grain structure.

From industrial perspectives, FSW is very competitive because it saves energy due to less heat input, prevents joints from fusion related defects, is cost effective and has better strength than TIG joint.

Acknowledgements

The authors are grateful to the department of Mechanical Engineering, L.D. College of Engineering, Ahmedabad for providing the facilities of CNC machine and material testing laboratory to carry out this investigation. The authors also thank Shri D.J. Bhavania for help rendered during the experimental investigation.

\section{References}

1. Cavaliere P, Squillace A and Panella F (2008) Effect of welding parameters on mechanical and microstructural properties of AA 6082 joints produced by friction stir welding. J. Materials Proc. Technol. 200, 364-372.

2. Chen C and Kovakevic R (2003) Finite Element modeling of friction stir welding-thermal and thermo mechanical analysis. J. Mac. Tool Manufac. 43, 13191326.

3. Dawes CJ (1995) An introduction to friction stir welding and its development. J. Weld Met. Fabric. 612.
4. Ericsson M and Sandstrom R (2003) Influence of welding speed on the fatigue of friction stir welds and comparison with MIG and TIG. J. Fatigue. 25,13791387.

5. Grong O (1997) Metallurgical modeling of welding, The institute of materials, $2^{\text {nd }}$ eds., London.

6. Lin DC, Wang TS and Srivatsan TS (2003) A mechanism for the formation of equiaxed grains in welds of aluminum-lithium alloy 2090. J. Mat. Sci. Engg. 335, 304-309.

7. Liu HJ, Fujii H, Maeda M and Nogi K (2003) Tensile properties and fracture locations of friction stir welded joints of 2017-T351 aluminum alloy. J. Mat. Proc. Technol. 142, 692-696.

8. Mondolfo LF (2002) Aluminum alloys-structure and properties. Butterworths, London.

9. Moreira PMGP, DeFigueiredo MAV and DeCastro PMST (2007) Fatigue behaviour of FSW and MIG weldments for aluminum alloys. J. Theoretical Appl. Fracture mech . 48,169-177.

10. Moreira PMGP, Santos T, Tavares SMO, RichterTrummer, Vilaca V and DeCastro PMST (2009) Mechanical and metallurgical characterization of friction stir welding joints of AA6061-T6 with AA6082T6. J. Mat. Design. 30,180-187.

11.Munoz AC, Ruckert G, Hunean B, Sauvage X, Marya $S$ (2008) Comparision of TIG welded and friction welded Al-4.5 Mg- $0.26 \mathrm{Sc}$ alloy. J. Materials Proc. Technol. 197, 337-343.

12. Norman AF, Drazhner $\mathrm{V}$ and Prangnell PB (1999) Effect of welding parameters on the solidification microstructure of autogenous TIG welds in an Al-CuMg-Mn alloy. J. Mat. Sci. Engg. 259, 53-60.

13.Sato YS, Kokawa H, Enomoto M and Jogan S (1999) Microstructural evolution of 6063 aluminum during friction stir welding. J. Metall. Mat. Trans. A 30, 24292437.

14.Svensson LE, Karlsson L, Larsson $\mathrm{H}$, Karlsson B, Fazzini M and Karlsson J (2000) Microstructure and mechanical properties of friction stir welded aluminum alloys with special reference to AA 5083 and AA 6082. J. Sci. Technol. Weld Joining. 5, 285-296.

15.Taban E and Kaluc E (2006) Microstructural and Mechanical properties of double-sided MIG, TIG and friction stir welded 5083-H321 aluminum alloy. J. Kovove Mater Met. Mater. 44, 25-33.

16. Thomas WM and Nicholas ED (1997) Friction stir welding for the transportation industries. J. Mat. Design. 18, 269-273.

17. Thomas WM, Nicholas ED, Needham JC, March MG, Temple smith P and Dases C (1991) Friction stir butt welding, International patent application no. PCT/GB92/02203 and GB (Patent application no. 9125978.86 Dec 1991).

18. Wei S, Hao C and Chen J (2007) Study of friction stir welding of 01420 aluminum-lithium alloy. J. Mat. Sci. Engg. A. 452-453, 170-177.
Research article

(CIndian Society for Education and Environment (iSee)
"Welding"

http://www.indjst.org
Shukla \& Shah Indian J.Sci.Technol. 